\title{
Modularity and variety in the customization of functional clothes for people with disabilities
}

\author{
Bruna Brogin¹; Maria Lúcia Ribeiro Okimoto ${ }^{1}$; Carlo Martino² \\ ${ }^{1}$ Post-graduation Program in Design, Sector of Arts Communication and Design, Federal \\ University of Paraná, XV Novembro, 1229, Curitiba, Paraná, Brazil \\ \{Bruna.Brogin, Maria.Lúcia.Ribeiro.Okimoto\} \\ ${ }^{2}$ Post-graduation Program in Planning, Design and Architecture Technology, Sapienza \\ Università di Roma, Flaminia, 70, Rome, Italy \\ \{Carlo.Martino\}
}

\begin{abstract}
The people with disabilities have sought for functional clothes that act as a piece of assistive technology, helping them to have autonomy when dressing. Some companies that sell functional clothes are inserted within the system of Mass Customization, and can be classified in six types: Totally custom, Co-design, Design options with standardized sizes, Design customization, Personalization, and Fit customization. Modularity and variety of choice that the costumers have regarding the design and fit of the pieces define these types. This research presents the analysis of twenty eight companies that sell functional clothing for people with disabilities, considering the levels of modularity and variety offered in the design and fit of the pieces. It also inserts each company analyzed in the Matrix of Modularity of Levels of Modularity/ Variety in Design and Fit Mass Customization. Results reveal that modularity is more present than variety, whether for design or for fit of the clothes.
\end{abstract}

Key words: Apparel mass customization - Modularity and Variety· Fit and

Design· Assistive technology

\section{Introduction}

The Brazilian Census indicated that $23.9 \%$ of the population has some kind of disability [1]. The average number of people with disabilities between 16-64 years in Europe is $13.11 \%$, with the lowest rate being Italy with 4.1 million people, or $6.1 \%$ of the population. The country with the highest rate is Norway with $20.1 \%$ of the population [2].

In the United States, in $2010,19 \%$ of the population had a disability (56.7 million people) according to [3]. In China, $6.1 \%$ of the population ( 83 million of people) are disabled [4]. In Africa, 80 million people are disabled according to [5]. This is a 
sample of the numbers collected by some countries that have signed the Convention on the Rights of Persons with Disabilities [6].

Most researches evaluates levels of disability, and usually present: low level, medium level or people who have difficulty to work, and high level or people who have difficulties while doing basic activities. Regardless of the type of disability that these people present, motor, visual, auditory, intellectual or multiple, they find barriers in daily living activities, because the environments, products and services are not accessible for all. [7] emphasize that clothing creates barriers in the full social engagement and relationships of people with disabilities, as well as in professional activities and everyday events.

Dressing is an activity present in everyone's routine, but still many people face difficulties in this task, among them: people with disabilities, elderly, pregnant, children, obese, sick people, among others [8]. A clothe designed to be functional in dressing, wearing and undressing is a product of assistive technology and, should be used with ease by people with disabilities.

According to [9], functional clothing is defined as clothes or fabrications specifically designed to deliver a predefined performance or functionality to the user, in addition to their normal functions of body coverage, protection and aesthetics.

The classification of functional clothing has seven segments; one of them is called Clothes for Special Needs and includes the function of the possibility of clothes for the elderly, children and people with disabilities [9]. This characteristic refers to favoring autonomy in the accomplishment of the activity, independence with regard to the caregivers, and quality of life, since its users feel empowered to live in different environments and perform various activities, such as studying, working, playing sports and attending public spaces.

Fashion companies that are part of the Mass Customization (MC) System, sell their products through the internet, allowing the personalization and customization of their products. They also work with small orders lots and fast deliveries, seeking to lower prices as much as possible to win customers, and generally deal with modular prefabricated parts [10]. MC is a hybrid production method between Mass Production, which produces large stocks of equal and cheap products for a wide range of customers, and Craft Production, which produces on demand unique and highly personalized pieces for unique customers, usually at high prices.

According to [11], the MC System for garments has two levels: modularization, that is, parts of other pre-defined and assembled parts; and the variety, which is the amount of choice the customers can make regarding the elements of the product that relate to their needs and desires. To allow this customization the company has a communication channel with the customer during the design and development of the product, which is often done through the internet and, in some cases, may requires a specialized professional. In clothing, modularity and variety are attributed to two main 
factors: design (model, fabric, colors, trims) and fit (measurements of patterns that form clothes) [12].

[11] outline six main types of MC applied to apparel: Totally Custom, Co-design, Design Options with Standardized Sizes, Design Customization, Personalization and Fit-customization. Each type of apparel-oriented MC presents a different amount of modularity and variety. The correct dosage of these choices made by the company (modularity), and the choices made by the customers (variety) can lead the company to commercial success. The adjustment between modularity and variety levels in a product can lead to the development of a niche of ideal products that are valuable to consumers and profitable to the company.

The combination of design and fit attributes and levels of modularity and variety can be a viable position for a company that wants to produce fashion for people with disabilities in order to meet the demands of customers and maintain the commercial viability of this process. [13] state that clients want their individual needs met, and companies can successfully implement MC through the use of virtual systems and the aid of a design manager to co-design the product with the customer.

Starting from the demand of functional clothes that attend disabled people, and from the need to understand the workflow of the companies that produce clothes for these users, this article aims to: analyze how companies that sell clothes for people with disabilities apply the concepts of modularity and variety used in the design and clothes' fit; check which of the six MC types these companies are applying; and insert the data collected in the Matrix of Levels of Modularity and Variety in Design and Fit Mass Customization, proposed by [11].

\section{Methodological Procedures}

This research has a theoretical nature and, according to [14], this type of research is conducted through the analysis of theories that may respond to a certain problem. This research also presents both quantitative and qualitative approaches. It is quantitative because it translates data into numbers using mathematical procedures such as average and percentage; and it is qualitative for describing in an inductive way the personalization for people with disabilities available in online fashion stores.

Regarding its objectives, this research can be considered descriptive. [15] states that this type of research aims to describe the characteristics of a phenomenon and to establish a relationship between variables. This research seeks to describe the characteristics of virtual stores that sell fashion for people with disabilities, and to relate the values of modularity and variety used.

The technical procedures go through the bibliographic research of books and articles which published content related to the design and development of fashion for people with disabilities. In this research 28 study cases of virtual stores that sell clothing for consumers with disabilities were conducted. 
The selection of the cases to be studied was done by searching in the internet for specific terms, such as "fashion for people with disabilities". This search was conducted using the same terms in English, Portuguese and Italian. Since the whole universe of stores that commercialize these products for adult women and men were approachable, all the websites of companies that presented apparel products were analyzed.

Children clothes, underwear, pajamas and accessories for assistive products, including textile articles (ex.: wheelchairs covers, bibs) were not analyzed. Websites of companies that did not allow the online purchase where not analyze as well. This refers to websites that offer models which can only purchased if the clients send an email, call to the store or go to the physical store. The list of companies analyzed is shown in table 1 in alphabetical order.

Table1: Fashion companies that produce functional clothes for disabled people. Obs.: Sites reviewed between November $17^{\text {th }} 2016$ and February $9^{\text {th }} 2017$.

\begin{tabular}{lll}
\hline & Companies' names & \\
\hline Able 2 Wear & Confort Clothing & Rolli Moden \\
Adaptations by Adrian & Design to Care & Rolling Wear \\
Adaptative Clothes Showroom & EZ Care Clothing & Rollitex Berlin \\
Adaptawear & Independent you & Shoppers Service \\
Adaptive Clothing Solutions & IZ Collection & Silvert's \\
Anitavee's & Lado B Moda Inclusiva & The Able Lable \\
Buck and Buck & Lydda Wear & Wardrobe Wagon \\
CAPR Style & Personal Touch & Wheelchair Jeans \\
Care Apparel Industries & Rackety's & \\
Clothes for Seniors & Rival Clothing & \\
\hline
\end{tabular}

\section{$3 \quad$ Modularity and variety of clothing for people with disabilities}

Modularity is defined as the use of pre-cut and pre-assembled parts for production, it represents modules defined by the company [16], which decrease the chances of customer choice. Variety is defined as the choices and specifications that customers make for the product, their needs and desires [17]; is what the customer determines.

The sooner the customer is inserted into the product development process, the more choices he or she can make [18]. If the customers are inserted at the beginning of the process they have the possibility to define the model, the fabric, and sizes. If they are inserted in the middle of the process, it would be possible only to define some colors and trims. If they are involved at the end of the process, they would be able to choose between modules pre-established by the company.

The websites described in table 1 were accessed in order to analyze the amount of modularity and variety present in each one. Each piece of clothing was selected and the purchase process was carried out in order to verify how many times the customer could choose between modules, how many specifications (variety) it was possible to 
make. It was also noted when the costumer had no option. The following clothes were analyzed: pants (and shorts), skirts, coats (jackets, blazers, jumpers...), shirts, blouses, dresses, body vests, jumpsuits and sets (top and bottom pieces sold together).

The products were classified according to gender as: male, female, and unisex. The aspects related to design were characterized as the options available for: model, color, fabric, fasteners, and lining. The fit aspects analyzed were: standard size, circumference of the waist, thorax, hip, and thigh, weight, and pathology (in order to promote a set of adjustments in the molds of clothing).

The aspects that indicate modularity represent the pre-determined options that the company gives to customers from a wide range of existing option. The aspects that indicate variety are represented by situations where customers can enter exactly what they want in the product. The same garment can use modularity for some design requirements and variety for others; and modularity for some fit requirements and variety for others. Among the 28 virtual stores analyzed, it was verified that 16 were from the United States, 5 from England, 2 from Germany, 2 from Scotland, 1 from Italy, 1 from Canada and 1 from Brazil. The authors believe that there are other stores in other countries, but these were not found due to the search language.

From the 28 companies analyzed, 13 have in their own website the date when they started working, which are 1930, 1951, 1974, 1980, 1987, 1990, 1992, 1993, 1995, 1997 (2 companies), 2009 and 2013. Some companies have been working for a long period of time, like 87 years, but there are also newer companies, working for only 4 years. These companies have been gone through many transformations due to changes in the market and, in the strategies of production and sale. Some have switched from selling directly to the final consumer to selling by catalog. Nowadays they sell through the internet and through representatives in order to adapt to the market demands and serve this niche of people that are seeking for specific products.

The analyzed companies sell clothes by categories, and the main categories for the purchase of the clothes are: men and women clothes (18 companies), adapted clothes (8 companies), name of the clothes' pieces (6 companies), anti-striped clothes (4 companies), open-back clothes (3 companies), for wheelchair users and for nonwheelchair users. They also have categories for winter, waterproof, for ostomized people, with elastic waist ( 2 companies for each category), clothes that help during transferring, thermal clothes, cooling clothes, sportive clothes, for elderly and seniors, hospital clothes, for people with Parkinson, Alzheimer and incontinence (1 company for each category).

In addition to these categories, the studied companies wrote in their website that they even produced clothes in order to attend people with other varieties of health specialties, like: Spinal Cord Injury, progressive illnesses, such Multiple sclerosis, Muscular Dystrophy, Motor Neuron Disease, head injury (Dementia, Cerebral Palsy), Hemiplegia or Amyotrophic Lateral Sclerosis, Post-Polio Syndrome, amputees, bedridden, people that have Arthritis (or another lack of finger dexterity) and can be 
helped with Velcro closures, people that suffer with bed sores, chronic fatigue and Diabetes. People with some other health specialties are focused during the production of the clothes, like people that need side zip clothes due to the limited movements, people that use Gastrostomy tube (feeding tube access) or ostomized people (that use catheters and colostomy bags), people with broken leg or that have another fractures, people that use intra venous tubes, people that need palliative or toileting care, people that need seated dressing, that have scoliosis, that use knee braces, clothes that help the caregiver work.

From the 28 companies surveyed, 13 produced men's, women's and unisex clothing, 11 produced men's and women's clothing, 2 produced men's clothes only and 2 produced women's clothes only. The average number of pieces offered to costumers is 69 , but the quantity of pieces offered by each company is varied, as shown in figure 1 .

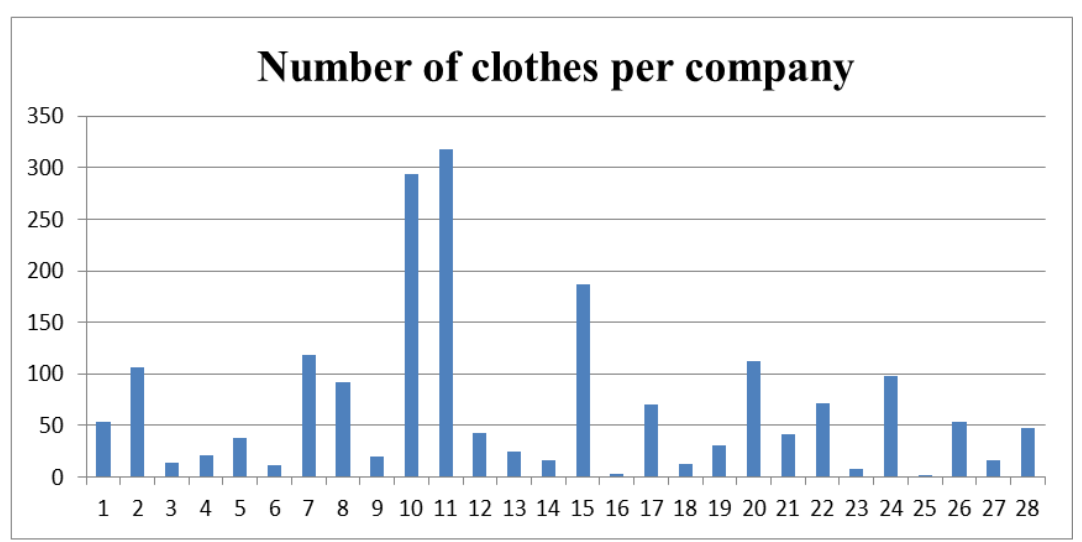

Fig. 1: Number of clothes offered by each company analyzed. Obs.: The company numbers are not related to the position of the companies' names in table 1.

The clothes offered more frequently were: pants (27 companies offer), coats (24 companies), and shirts and blouses (18 companies). The clothes offered less often were: body vests ( 3 companies offer) and jumpsuits (10 companies), as shown in figure 2. The data show that the variety of clothes serves people with various types of disabilities, but certain types of specific clothes, such as body vests and jumpsuits, have little offer of products. 


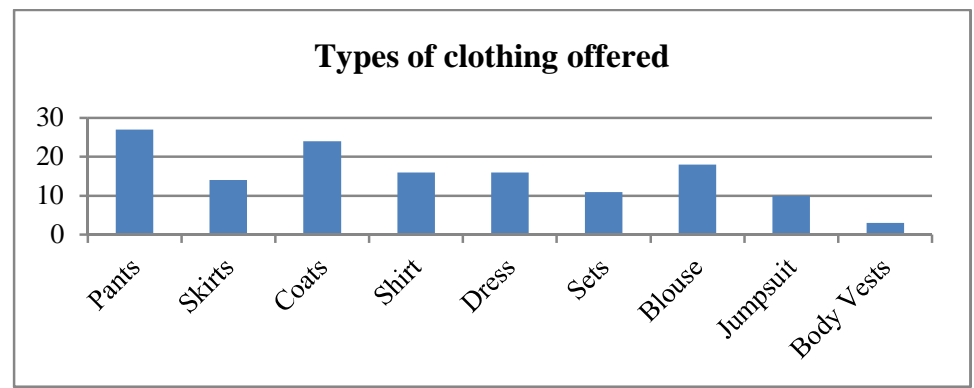

Fig. 2: Number of companies that offer each type of clothes.

Table 2 provides the data of how many pieces were offered by each company, the analyzed clothes' totals and the amount of modularity / variety referring to the fit / design for the totals.

Table 2. Number of pieces offered by each company by model; totals and modularity / variety for fit / design referring to totals presented.

\begin{tabular}{|c|c|c|c|c|c|c|c|c|c|}
\hline $\begin{array}{l}\text { Companies' } \\
\text { numbers }\end{array}$ & Pants & Skirts & Coats & Shirts & Dress & Sets & $\begin{array}{l}\text { Blouses/ } \\
\text { T-shirts }\end{array}$ & Jumpsuits & $\begin{array}{l}\text { Body } \\
\text { vests }\end{array}$ \\
\hline 1 & 31 & 2 & 18 & 2 & - & - & - & - & - \\
\hline 2 & 19 & 3 & 16 & 12 & 20 & 13 & 20 & 3 & - \\
\hline 3 & 9 & 1 & 4 & - & - & - & - & - & - \\
\hline 4 & 7 & 2 & 2 & 7 & 2 & - & 1 & - & - \\
\hline 5 & 14 & 4 & 3 & 11 & 5 & - & 1 & - & - \\
\hline 6 & - & - & 1 & - & - & - & - & - & 10 \\
\hline 7 & 109 & - & 10 & - & - & - & - & - & - \\
\hline 8 & 73 & - & 6 & 1 & - & - & 12 & - & - \\
\hline 9 & 16 & - & - & - & - & - & 4 & - & - \\
\hline 10 & 53 & 6 & 27 & 10 & 22 & 29 & 147 & - & - \\
\hline 11 & 67 & 1 & 42 & 32 & 42 & 33 & 80 & 20 & 1 \\
\hline 12 & 25 & 2 & 1 & 6 & - & - & 9 & - & - \\
\hline 13 & 1 & 7 & 8 & 3 & 6 & - & - & - & - \\
\hline 14 & 6 & - & 4 & - & - & 6 & - & - & - \\
\hline 15 & 42 & 3 & 12 & 15 & 20 & 48 & 37 & 10 & - \\
\hline 16 & 3 & - & - & - & - & - & - & - & - \\
\hline 17 & 12 & 1 & 6 & 5 & 6 & 19 & 17 & 4 & - \\
\hline 18 & 5 & - & 1 & - & 2 & - & 3 & 2 & - \\
\hline 19 & 3 & 2 & 5 & - & 11 & 3 & 5 & 2 & - \\
\hline 20 & 22 & - & 34 & 14 & 19 & 11 & 11 & 2 & - \\
\hline 21 & 16 & - & 1 & 10 & - & - & - & 15 & - \\
\hline 22 & 17 & - & 18 & 3 & 5 & 8 & 20 & - & - \\
\hline 23 & 2 & - & - & - & - & - & 6 & - & - \\
\hline 24 & 21 & - & 19 & 10 & 7 & 7 & 30 & 4 & - \\
\hline 25 & 2 & - & - & - & - & - & - & - & - \\
\hline 26 & 8 & 1 & 8 & - & 11 & 10 & 14 & 2 & - \\
\hline 27 & 2 & 2 & 3 & 2 & 2 & - & 5 & - & - \\
\hline 28 & 12 & - & 9 & - & 2 & - & 9 & - & 16 \\
\hline Total & 597 & 37 & 258 & 143 & 182 & 187 & 431 & 64 & 27 \\
\hline $\begin{array}{l}\text { Modularity } \\
\text { in fit }\end{array}$ & 586 & 37 & 251 & 143 & 182 & 187 & 431 & 64 & 27 \\
\hline Variety in & 19 & 0 & 9 & 1 & 0 & 5 & 1 & 0 & 11 \\
\hline
\end{tabular}

fit 


\begin{tabular}{llllllllll}
$\begin{array}{l}\text { Modularity } \\
\text { in design }\end{array}$ & 434 & 26 & 210 & 106 & 130 & 149 & 305 & 51 & 27 \\
$\begin{array}{l}\text { Variety in } \\
\text { design }\end{array}$ & 45 & 4 & 40 & 28 & 41 & 30 & 45 & 9 & 0 \\
\hline
\end{tabular}

The data presented in table 2 show that the companies with the largest variety of products were the companies 11,15 and 17 , and the companies with the smallest variety of products were companies 16 and 25 (one type of product) and 7 and 23 (2 types of products). The most popular clothes were pants, totalizing a total of 597 products, followed by blouses (431 products). The least popular pieces were body vests ( 27 products) and skirts (37 products).

Regarding the amount of modularity in the fits, it was verified that the majority of the pieces had modular fits, only 11 pants and 7 coats were not sold by any system of predefined fits. Some pieces combined predefined fits with customizable fits. It was also found that only 19 pants, 9 coats, 1 skirt, 5 sets, 1 blouse and 11 body vests had the option of variety for fits.

The modularity of fits in the clothing for people with disabilities was verified in the clothes offered in the following modules: total size of clothing ( S, M, L ...), inseam length, increase in waistband height, waist circumference, short or long sleeve, and long sleeve length. The variety in fit was analyzed in the options of measures of: waist circumference, inner and outer thorax, abdomen, hip, thigh and calf, back length, leg, crotch, weight, pathology, fits of the lateral opening of the legs in the pants, and fit and position of the opening in the clothes for ostomized people.

Regarding the design of the pieces, it was verified that $74 \%$ of the clothes have design modules, which usually refers to the color option for the products. However there are other options, such as: choosing a second color option, in case that the color chosen is not available and the company chooses to ship the product in the second chosen color instead of producing the first option, in order to expedite the order faster. On large orders, made by institutions that take care of the disabled or elderly people, it is possible to delegate the option of combining the colors of top and bottom clothes for the selling company, indicating only the desired shade range (light, dark, pastel, bright and assorted). It is also possible to choose the color of parts of the clothes (for example, the sleeve).

Clients could also opt between different fabrics (different compositions, wefts and forms of preservation), as well as lining fabrics, single or double fabric layers, and patterns. As for the trims, customers can choose the type of zipper (type of handle), apparent or hidden buttons (sewing mode), buckle insertion, insertion point of the label, shoulder opening model on the blouses, insertion of Velcro on collar and cuff of shirts.

Regarding pants, customers can choose from regular models or from others with adaptations for wheelchair users, pocket or non-pocket insertion (size and position), drawstring insertion on the pant waist, type of fly opening (from the right or left), belt 
loops around waist for belt use, pull loops on each side of the waist for easier dressing when pulling up pants, and zippers on each leg on the lower part of the outside leg seam. There are companies that include the option of lowering the side zipper of the legs or the front zipper of the pants (from the waist), widening or narrowing the lower part of the legs, inserting elastic in the hem, and choosing for stitches open on the back seam (to prevent pressure sores on wheelchair users). The companies that present these options emphasize that the insertion of some modules would imply a surcharge on the product, and include the specifications at the end of the purchase order.

The variety of design is present in $12 \%$ of the products, and refers to the possibility of adding the name and the room of the user in the clothe label. This option was indicated for purchases made by institutions that take care of elderly or people with disabilities. In almost $14 \%$ of the products, companies present neither modularity nor variety for the design; those are pieces without any design option.

\section{Types of mass customization employed by apparel companies that produce for people with disabilities}

[11] highlight six types of MC based on modularity and variety applied to clothes, as presented in table 3 .

Table 3: Types of mass customization in previous research based on levels of modularity and variety. Fragment of [11] p. 204.

\begin{tabular}{|c|c|c|c|}
\hline $\begin{array}{l}\text { Level of } \\
\text { Modularity and Variety }\end{array}$ & $\begin{array}{c}\text { [19] } \\
\text { (Apparel) }\end{array}$ & \multicolumn{2}{|c|}{$\begin{array}{c}\text { [12] } \\
\text { (Apparel) }\end{array}$} \\
\hline $\begin{array}{l}\text { Very low modularity and } \\
\text { very high levels of variety }\end{array}$ & Totally Custom (TC) & \multirow{4}{*}{$\begin{array}{l}\text { Design } \\
\text { Customization } \\
\text { (DC) }\end{array}$} & \multirow{5}{*}{$\begin{array}{l}\text { Fit- Customization } \\
\text { (FC) }\end{array}$} \\
\hline $\begin{array}{c}\text { Low modularity and } \\
\text { mid to high levels of variety }\end{array}$ & \multirow{2}{*}{ Co-design (CD) } & & \\
\hline $\begin{array}{l}\text { Medium modularity and } \\
\text { medium levels of variety }\end{array}$ & & & \\
\hline $\begin{array}{l}\text { High modularity and } \\
\text { low levels of variety }\end{array}$ & $\begin{array}{c}\text { Design options with } \\
\text { standardized sizes (DS) }\end{array}$ & & \\
\hline $\begin{array}{l}\text { Very high modularity with } \\
\text { limited or no variety }\end{array}$ & & $\begin{array}{l}\text { Personalization } \\
\text { (P) }\end{array}$ & \\
\hline
\end{tabular}

In order to know the kind of MC used by each company, the following procedure was performed: all the pieces of each company that had fit modularity were counted, all pieces that had fit variety were counted, all pieces that had design modularity were counted, and all the pieces that had design variety were counted. After that, the percentage that each represented in relation to the total of pieces produced by the respective company was verified. In this way, each company could have $200 \%$ modularity (100\% fit modularity and $100 \%$ design modularity), and $200 \%$ variety 
(100\% fit variety and $100 \%$ design variety). The percentages related to modularity were added, as well as the percentages of variety.

As table 3 presents 5 levels of modularity and variety (very low, low, medium, high and very high), the following rule was used: $0-40 \%$ modularity or variety = very low, $41-80 \%$ modularity or variety = low, $81-120 \%$ modularity or variety = medium, $121-160 \%$ modularity or variety = high, 161 to $200 \%$ modularity or variety = very high. With this rule it was possible to establish the amount of modularity and variety employed by each company and apply the six MC types previously described.

After the companies already classified in the more specific types of MC have been excluded (TC, CD, DS, P), the design and fit data of the companies that were in the DC and FC intervals were analyzed. This was done in order to distinguish whether a company had more design or fit customization and due to the amplitude of the intervals of these types of MC (table 3).

After carrying out the above procedure, it was verified that the companies' analyzed could not be introduced into the types TC and CD. The company 14 could be categorized in the Design Options with Standardized Sizes type (very high modularity and low variety). Companies 2, 24 and 26 cold be included in the category Design Customization (due to very high modularity and medium variety). Companies $1,7,12,16^{1}$ and 19 cold be added to the type Fit Customization, and all other companies could be categorized in Personalization (very high modularity and very low variety). According to the matrix proposed by [11] the disposition of the companies analyzed could be represented as shown in figure 3 .

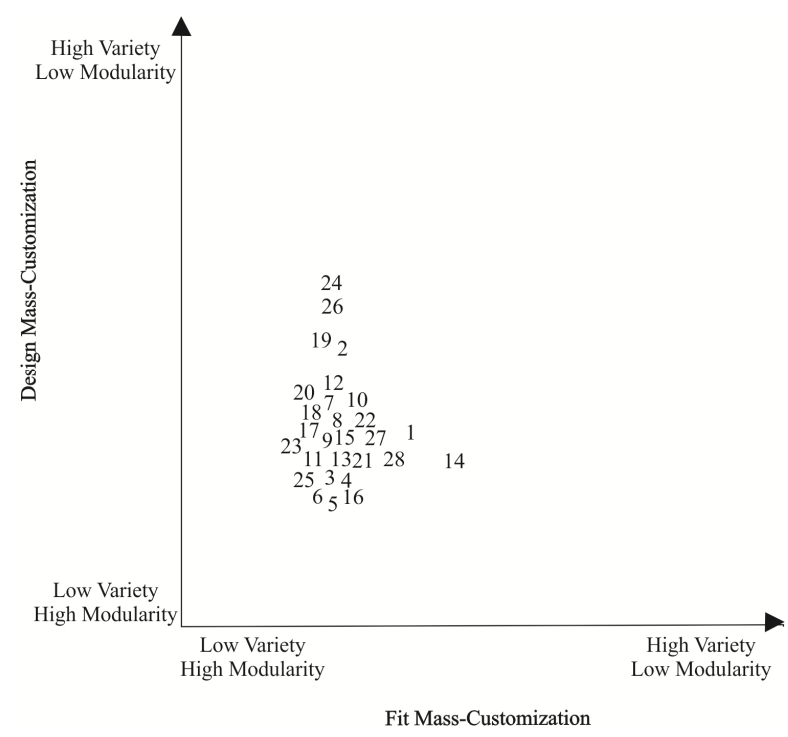

\footnotetext{
${ }^{1}$ Company 16 presents medium modularity and variety, but after analyzing the company's data, it was found that the products could not be framed in Co-design.
} 
Fig. 3: Disposition of the analyzed companies according to the modularity and variety levels of design and fit of clothes in the Matrix developed by [11] .

Figure 3 reveals that no company stands out regarding the variety of design or fit, most are in the lower left quadrant, demonstrating high or medium modularity of fit and design. Only the companies 24 and 26 present in the upper left quadrant, demonstrating a slightly greater variety of design than the others do.

\section{Conclusion}

The data collected during this research are not related to a static situation of clothing companies for people with disabilities, because at any moment they can change the collection, offer new products, or starting using a different purchase system. However, from the data collected and analyzed during the research period, the authors concluded that the majority of the companies that produce clothes for people with disabilities predominantly present modularization (74\% of clothes to design and $99 \%$ of clothes to fit).

The variety is used more in the design ( $12 \%$ of clothes) than in the fit $(2 \%$ of clothes) of the clothes. Among these companies none could be classified as Totally Custom or Co-design, which indicates that customers are usually only able to participate in the final stages of the development process of their products. One company $(3,5 \%)$ can be classified in Design options with standardized sizes, three in Design Customization (10,7\%), five in Fit-Customization $(17,8 \%)$ and 19 in Personalization $(67,8)$.

Some companies are willing to allow even further customization on their clothing than the available on the website, but they ask to their customers to send an email or call to complete the order. This fact indicates a lack of an online system that enables more specific customizations to be made in the clothing.

The data collected reveal how the apparel companies that produce clothing for people with disabilities work. Companies that aim to stand out in this sector can propose a new approach to customers. This could be done through a new marketing position and a new development, production and sale strategy that meets the market needs for products with a high degree of specificity.

Future work can investigate how people with disabilities and their caregivers would like to get involved in the process of developing their clothes, and from that point, verify if a MC strategy that allows more customization could add customers to the process of clothing development.

[20] found that the willingness of customers to co-design comes from the opportunity to experience the appearance and enhance individuality, and can be achieved through a system that provides an exciting experience during the creation of a unique product. Future studies may also verify whether if same motivations are 
valid for people with disabilities, or whether factors such as the need for specific products, would make them engage in the co-design of their clothes.

\section{References}

1. IBGE - Instituto Brasileiro de Geografia e Estatística.: Censo Demográfico 2010 Características gerais da população, religião e pessoas com deficiência. IBGE, São Paulo (2010)

2. EUROSTAT.: Disability Statistcs - prevalence and demographics (2012), http://ec.europa.eu/eurostat/statistics-explained/index.php/Disability_statistics__prevalence_and_demographics

3. United States Centre Bureau.: Nearly 1 in 5 people have disability in U.S. Census Bureau Reports (2012), https://www.census.gov/newsroom/releases/archives/miscellaneous/cb12134.html

4. United Nations.: Disability Enable (2007), http://www.un.org/issues/m-disabl.asp

5. African Studies Centre Leiden.: Disability in Africa http://www.ascleiden.nl/content/webdossiers/disability-africa

6. United Nations.: Convention on the rights of persons with disabilities (2006), http://www.un.org/disabilities/convention/conventionfull.shtml

7. Kabel, A., Dimka, J, McBee-Black, K.: Clothing-related barriers experienced by people with mobility disabilities and impairments. App. Erg. 59, 165--169 (2017)

8. SDPD - Secretaria dos Direitos das Pessoas com Deficiência de São Paulo.: Moda Inclusiva (2012)

9. GUPTA, D.: Functional Clothing - Definition and Classification. Ind. J. Fib. Tex. Res. 36, 321--326 (2011)

10. Pine, B. J.: Mass Customization the new Frontier in Business Competition. Havard Business School Publishing, Boston, (1993)

11. Yang, J., Kincade, D. H., Chen-Yu, J. H.: Types of Apparel Mass Customization and Levels of Modularity and Variety Application of the Theory of Inventive Problem Solving. Clot.Tex. Res. J. 33, 199--212 (2015)

12. Burns, L. D., Bryant, N. O.: The business of fashion Designing, manufacturing, and marketing. Fairchild Publications, New York (2005)

13. Ulrich, P. V., Anderson-Connell, L. J., Wu, W.: Consumer co-design of apparel for mass customization. J. Fas. Mark. Man. Int. J. 7, 398--412 (2003)

14. Silva, É. L., Menezes, E. M.: Metodologia da pesquisa e elaboração da dissertação. UFSC, Florianópolis (2005)

15. Gil, A. C.: Como elaborar projetos de pesquisa. Atlas, São Paulo (1991)

16. Duray, R.: Mass customization origins Mass or custom manufacturing. Int. J. Oper. Prod. Man. 22, 314--328 (2002)

17. Ahlstrom, P., Westbrook, R.: Implications of mass customization for operations management: An exploratory survey. Int. J. Oper. Prod. Man. 19, 262--274 (1999)

18. Senanayake, M. M., Little, T. J.: Mass customization Points and extent of apparel masscustomization. J. Fas. Mark. Man. 14, 282--299 (2010)

19. Anderson-Connell, L. J., Ulrich, P. V., Brannon, E. L.: A consumer-driven model for mass customization in the apparel market. J. of Fas. Mark. Man. 6, 240--258 (2002)

20. Fiore, A. M., Lee, S., Kunz, G.: Individual differences, motivations, and willingness to use a mass customization option for fashion products. Eur. J. Mark. 38, 835--849 (2004) 